\title{
Review Article \\ Human Bodies Bequest Program: A Wake-Up Call to Tanzanian Medical Schools
}

\author{
Erick J. Mazyala, ${ }^{1}$ Makaranga Revocatus, ${ }^{2}$ Mange Manyama, ${ }^{1}$ \\ Sifael Msuya, ${ }^{1}$ Peter Rambau, ${ }^{3}$ Emmanuel Kimwaga, ${ }^{1}$ Ndulu Magelle, ${ }^{1}$ \\ Yanga Machimu, ${ }^{4}$ Mathayo Joshua, ${ }^{1}$ and Cassian C. Magori ${ }^{5}$ \\ ${ }^{1}$ Department of Anatomy, School of Medicine, Catholic University of Health and Allied Sciences (CUHAS), \\ P.O. Box 1464, Bugando, Mwanza, Tanzania \\ ${ }^{2}$ Department of Anatomy, Peramiho School of Medicine, Archbishop James University (AJUCO), Songea, Tanzania \\ ${ }^{3}$ Department of Pathology, School of Medicine, Catholic University of Health and Allied Sciences (CUHAS), Bugando, \\ Mwanza, Tanzania \\ ${ }^{4}$ Department of Library Service, Catholic University of Health and Allied Sciences (CUHAS), Bugando, Mwanza, Tanzania \\ ${ }^{5}$ Department of Anatomy, Faculty of Medicine, Saint Francis University College of Health and Allied Sciences (SFUCHAS), \\ Ifakara, Morogoro, Tanzania
}

Correspondence should be addressed to Erick J. Mazyala; mazyala@gmail.com

Received 4 August 2014; Revised 6 October 2014; Accepted 24 October 2014; Published 18 November 2014

Academic Editor: Luis-Alfonso Arráez-Aybar

Copyright (C) 2014 Erick J. Mazyala et al. This is an open access article distributed under the Creative Commons Attribution License, which permits unrestricted use, distribution, and reproduction in any medium, provided the original work is properly cited.

Introduction. Studying anatomy through dissection of human cadavers requires a regular supply of human bodies. Tanzanian medical schools depend entirely on collecting unclaimed bodies in hospital mortuaries. This method is no longer reliable. This study aimed at evaluating sources and profile of cadavers in Tanzanian medical schools and addressing challenges and suggests appropriate lasting solutions. Methods. Seven spreadsheets were sent electronically to seven medical schools in Tanzania to capture data related to sources and profiles of cadavers received. Only 2 out of 7 responded timely. Results. $100 \%$ of all cadavers in Tanzanian medical schools are unclaimed bodies of black population. Female cadavers accounted for 0-20\%. About 9 days elapse before embalmment of cadavers. Conclusion. It is the time to jump onto body bequest wagon.

\section{Introduction}

Anatomy has been shown to be one of the core subjects for medical students, parallel to physiology and pharmacology [1]. Cadaver dissection is regarded to be the fundamental anatomy teaching and learning tools for medical student [2]. Few studies that have examined the sources of cadavers in Africa reported the unclaimed bodies to be the main source for cadaver in medical schools throughout the continent [3-7]. Also some of these studies reported that bequest body program has only been practiced in Zimbabwe, Ghana, Malawi, and South Africa; the rest of medical schools in Africa depend on unclaimed bodies [6]. None of such studies has been done in Tanzania.
The source of cadavers in all medical schools in Tanzania is solely unclaimed bodies from hospital mortuaries. Rules 49 under section 128 of chapter 16 in Tanzania penal code of the laws governs and regulates the use of unclaimed bodies for biomedical studies, and that there is no law provision for whole body donation. The supply of bodies was adequate in the past when there was only one medical school in Tanzania that also enrolled few medical students. In the past two decades, Tanzania has witnessed an increase in number of medical schools from one to seven along with parallel massive expansion of students' enrollments. These medical schools maintained cadaver dissection as a fundamental teaching tool in anatomy. This has profound implication on the availability and adequacy of human bodies to quench the exploded 
cadaver demand to all medical schools. Interestingly, the same source for cadaver's procurement has been maintained, being unclaimed bodies from hospitals mortuaries. The effect has been noted, as there has always been shortage of required number of suitable cadavers available to meet huge numbers of first year medical students enrolled in each year. Medical students in Tanzania have been overcrowded on each dissection table in pursuit of the much-needed gross anatomical knowledge. This study was done to evaluate the sources and profile of cadavers in Tanzanian medical schools and to discuss the associated challenges and lasting solutions related to utilization of unclaimed bodies.

\section{Materials and Methods}

A spreadsheet was sent electronically to all 7 medical schools in Tanzania to capture information of all cadavers that were received during the past 8 years. It contained columns for capturing information such as academic year, total number of cadavers received in a year for previous eight years, sex composition of cadavers, age at the time of death, date of death, cause of death, status of cadaver identity (known by name or unknown), date of reception/embalmment, and circumstances surrounding death. Data received were analyzed and presented as mean, mode, and percentage in results of the study.

\section{Results}

Only 2 out of 7 medical schools responded by returning the partially filled reports (28.6\%). For the purpose of confidentiality, respondents one and two, from now on, will be referred to as medical school 1 and medical school 2 (2nd medical school), respectively. Medical school 1 is only 5 years old and enrolls about 100 medical students per year. Medical school 2 is 12 years old with annual medical student's enrollment of about 150. In the past 8 years, more than 1000 medical students have learned anatomy using available unclaimed bodies at medical school 2 .

3.1. Profile of Cadavers. All received cadavers from all medical school belonged to black population and were all unclaimed. The age at the time of death ranged from 10 to 73 years; the exact age of some cadavers could not be found and hence they were referred to as adult. Cadavers with known identity received at 2 nd medical school were $74(80.4 \%)$ and 18 (19.6\%) were unknown.

None of fetuses were received in the past 5 or 8 years at any of the two medical schools responded as shown in Table 3. Of the two respondents, medical school 2 provided information regarding total number and sex of cadavers annually and circumstances surrounding deaths, identity of cadaver, the time of death, and time of receiving cadaver. Cadavers were embalmed immediately after being received. Calculating time elapsed before embalmment was possible by subtracting the time of death from the time of cadaver reception at medical school. All other information regarding cadaver was missing in their records.
TABLE 1: Sex profile of cadavers received at medical college 1 in the past five years.

\begin{tabular}{lccc}
\hline \multirow{2}{*}{ Year } & \multicolumn{2}{c}{ Sex of cadaver } & Total \\
& M & F & \\
\hline 2010 & 4 & 1 & 5 \\
2011 & 8 & 0 & 8 \\
2012 & 10 & 1 & 11 \\
2013 & 10 & 1 & 11 \\
2014 & 15 & 0 & 15 \\
\hline Total & $47(94 \%)$ & $3(6 \%)$ & $50(100 \%)$ \\
\hline
\end{tabular}

Note that there is no female cadaver in the years 2011 and 2014.

TABLE 2: Sex profile of cadavers received at medical college 2 in the past eight years.

\begin{tabular}{lccc}
\hline Year & \multicolumn{2}{c}{ Sex of cadaver } & Total \\
\hline 2007 & M & F & \\
2008 & 8 & 1 & 9 \\
2009 & 5 & 1 & 6 \\
2010 & 11 & 3 & 14 \\
2011 & 12 & 2 & 14 \\
2012 & 5 & 3 & 8 \\
2013 & 8 & 4 & 12 \\
2014 & 11 & 1 & 12 \\
\hline Total & 14 & 3 & 17 \\
\hline
\end{tabular}

Note: 3 male cadavers were reclaimed giving the overall total of 89 cadavers. The reclaimed cadaver is $3.3 \%$.

\section{Discussion}

Respondent rate of $28.6 \%$ is the limitation of this study. Also the returned spreadsheets missed some information and thus forced utilizing data mostly from medical school 2. Incomplete record taking and keeping is a big challenge and has precluded capturing of most data particularly from medical school 1 . However, data obtained is generally representative to all Tanzanian medical schools.

Both of medical schools depended entirely on unclaimed bodies for cadaver dissection. The use of unclaimed bodies for dissection in medical schools has been considered to be economically suitable, since the government escapes burial expenses and at the same time medical school objectives are met through teaching anatomy and research by dissection [8]. Both medical schools have fairly adequate supply of male cadavers.

Our results show unsteady supply of cadavers in both medical schools and more seriously are lacking female cadaver in some years as noted in Tables 1 and 2 . These findings concur with results from studies elsewhere, whereby one of the key problems that have been reported to be inherent with utilization of unclaimed bodies is relative unsteady supply of cadavers in general and scarcity of female cadaver $[4,5,7]$. Absent female cadavers deny medical students an opportunity to appreciate the gross anatomy of female pelvis and reproductive system shown in Table 1. Another key 
TABLE 3: Age profile of cadaver received at medical school 2 for the past 8 years.

\begin{tabular}{lcc}
\hline Age & Frequency & Percentage \\
\hline $0-10$ & 1 & 1.1 \\
$11-20$ & 7 & 7.6 \\
$21-30$ & 12 & 13 \\
$31-40$ & 14 & 15 \\
$41-50$ & 9 & 9.8 \\
$51-60$ & 6 & 6.5 \\
$61-70$ & 4 & 4.3 \\
$71-80$ & 2 & 2.2 \\
Adult & 37 & 40.2 \\
\hline Total & 92 & 100 \\
\hline
\end{tabular}

Note: age group indicated as "Adult" included all cadavers with unknown exact age.

TABLE 4: Circumstances surrounding death of cadaver received at medical school 2 in the last eight years.

\begin{tabular}{lcc}
\hline Death context & Frequency & Percentage \\
\hline Hospital & 46 & 50 \\
Police case & 38 & 41.3 \\
Prison & 8 & 8.7 \\
\hline Total & 92 & 100 \\
\hline
\end{tabular}

Note: police cases and prison give a combined percentage of 50\%. Most of hospital unclaimed bodies belonged to individuals that were admitted at psychiatric and trauma (accidental) victim's wards.

problem observed in this study related with utilization of unclaimed bodies is their potential risks of being reclaimed by relatives of the deceased. This has been noted in Table 2 from medical school 2 whereby 3 bodies were reclaimed, accounting for $3.3 \%$ of all bodies procured in 8 years. This further hampers efforts to secure adequate cadavers for gross anatomy training to medical students. Interestingly none of received cadavers in the two medical schools included fetuses. This has negative consequences in learning of developing organs by medical students as shown in Table 3 .

In Tables 2 and 3, males, 20-40 years old, are at the highest chance of ending up on dissecting table without their consent in Tanzania. This is the most vibrant, high risk taker, and productive male age group and as seen in Table 4 and Figure 1 is also involved most with unlawful activities. This finding is similar to those reported by Akinola [5] and Osuagwu et al. [7] in Nigeria whereby most unclaimed bodies belonged to individuals who died during duels with law enforcement agents. Thus prisoners and bandits are the major contributors of unclaimed bodies for anatomical dissections.

In the present study, most of cadavers stayed for an average of 9 days before they were embalmed as seen in Figure 2. This renders majority of unclaimed bodies to be relatively of poor quality. By the time unclaimed bodies are released to be fixed for training, most of tissues and organs had lost their freshness and fungal growth is a common problem. These complicate the learning experience

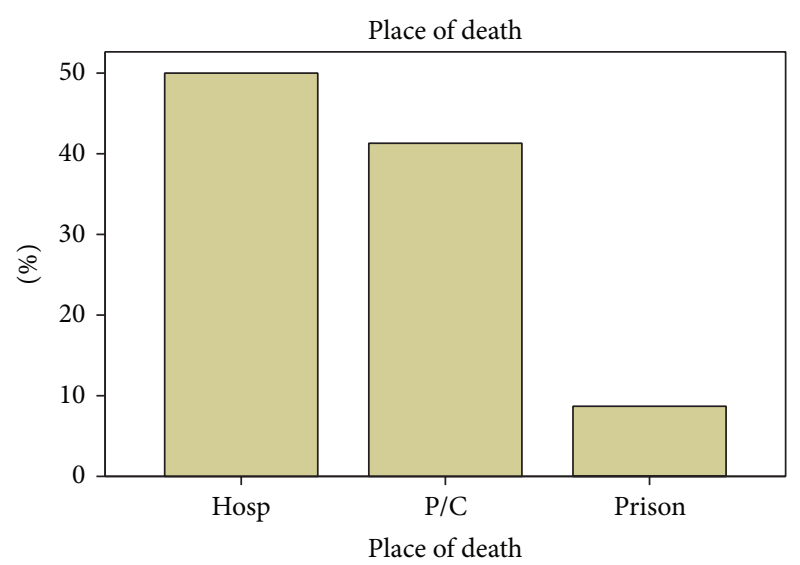

Hosp $=$ hospital, and $\mathrm{P} / \mathrm{C}=$ police case

FIGURE 1: Bar chart showing context of death of cadaver received at medical school 2 in the past 8 years.

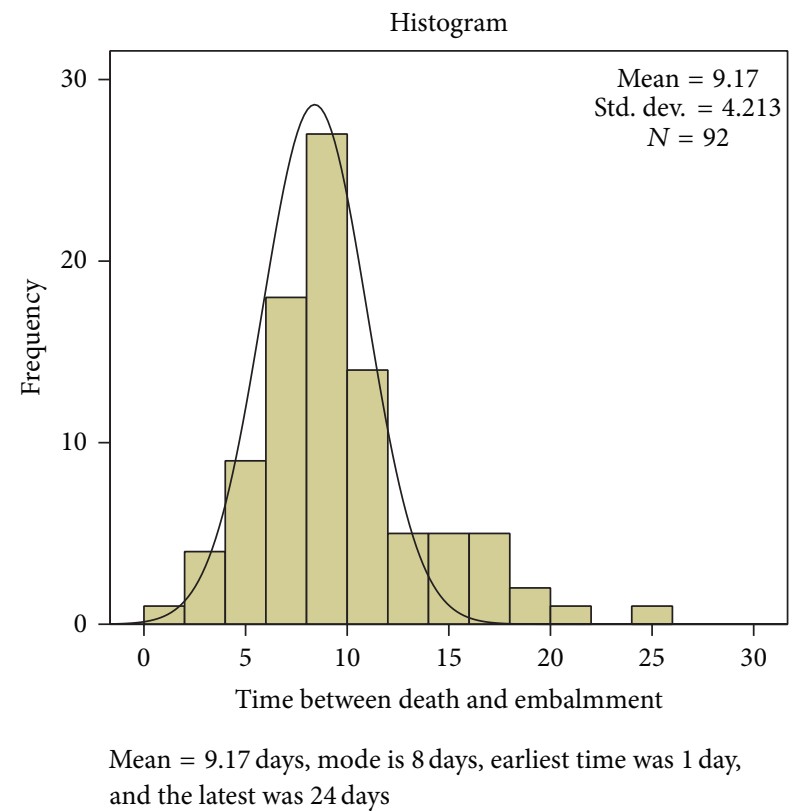

Figure 2: The time elapse from death to embalmment of cadaver received at medical school 2 .

of medical students. Appreciating already damaged tissues during dissection is much difficult than it is in fresh cadavers.

In the current study, the deceased never consented for anatomical dissection and these pose serious ethical concerns. Tanzanian and most African medical schools never went through an era whereby scrambling for bodies of decapitated convicted criminals were common practices, nor participated in grave-robbing and human murders for cadavers' pursuit. However, continuing ethically dubious practices of utilizing unclaimed bodies draw African medical schools close to the tainted past.

The most promising and lasting solution to address the above problems is the initiating body bequest program in Tanzania and Africa. Body bequest program has transformed 
procurement of cadavers in many medical schools globally. Since the introduction of the Anatomy Act of 1832, in England, and the Uniform Anatomy Gift Act (UAGA) in 1968 in USA, the UK has achieved $100 \%$ dependence on donated bodies whereas north America, New Zealand, and South Africa have achieve more than $80 \%$ dependence on donated bodies $[5,6,9]$.

Literatures elsewhere have shown some reservations on the use of unclaimed bodies for anatomical dissections. Cornwall et al. [3], Jones and Whitaker [8], and Gangata et al. [6] referred to the use of unclaimed bodies as "ethically dubious practice." The time delays before fixation, seen in Figure 2 above in present study; make unclaimed bodies being of relative poor quality. Most of unclaimed bodies belong to social outcast, convicted criminals, and marginalized, impoverished, homeless and mentally retarded individuals. Continue utilizing unclaimed bodies for dissection by medical schools will mean deliberate targeting and hence exploiting individuals belonging from these groups $[8,10$, 11]. This is ethically impermissible course even though it is legalized. We need to shake off the tainted past of anatomy training history and become more vigilant on ethical matters. Perhaps it is the time that Tanzania medical schools take a jump on the bequest program "wagon" which most of peer medical schools in the globe had long opted for.

\section{Bequest or Whole Body Donation Program}

Whole body donation is an informed and free act of giving one's whole body after death for medical education and research [12]. Apart from cleared ethical concerns, donated bodies would generally be received within five hours and hence still be fresh and are of better quality. According to Prakash et al., [13] body donation is supposed to be done voluntarily without expectations of financial gain. In recent past, some entrepreneur companies in USA have been established and are legally operating to collect donated bodies by providing financial incentives to donors or donor's relatives [14]. If not controlled, monetary incentives for donating body may be transformed to body selling and buying business. This has potential to trigger human murders for profit. In Tanzania, there is no law enacted related to body donation; the only trace of donation permitted by law from dead body after obtaining consent from the next of kin is provided by rule number ten (10) under section 128 of chapter 16 in Tanzania penal code of the laws, and is only limited to donation of some viable tissues.

\subsection{Key Points in Establishing Bequest Programs in Tanzania}

5.1.1. Lead in Time Is Long. England spent more than a century, from 1832 to 1944 to achieved only 3\% dependence on body donation [15]. In addition, more than six decades were required for England to rise from 3\% to 100\% dependency on willful body donations as a sole source for cadavers in medical school. In USA, it took about four decades from 1968 , with the "Uniform Anatomy Gift Acts" (UAGA) enacted, to 2010 , to achieve $80 \%$ dependency on willful body donations as source of cadavers $[6,16]$. It takes substantial time before an individual decides on registering for body donation program. Cornwall et al. [3] found an average of ten years from initial awareness to actual registration. Moreover, it takes a lifetime before an individual dies. The impacts of the program need significant long lead in time. Obviously, establishing bequest program takes time to materialize; Tanzania medical schools opt for bequest program now.

5.1.2. Making the Public Aware Is a Key. Lack of awareness is the major hindrance to body donation $[3,12]$. The starting point is raising awareness on the existence of this willful whole body donation practice. The program is completely new even to the anatomists in Tanzanian medicals schools. Raising awareness to anatomists themselves is a key for establishment of the program in Tanzania. Lack of an organized anatomical professional forum in Tanzania is another challenge. This denies a united voice among anatomists in Tanzania. We need a professional forum whereby common concerns can be addressed. Probably, it is now the time that anatomists in Tanzania form Anatomical Society of Tanzania (AST), where burning issues related to core anatomical affairs will be discussed. Having legally operating AST, it will be very instrumental in dealing with sensitive issues such as establishing bequest program. Through AST, state policies can easily be mended through raising awareness among politicians to effect necessary changes in laws and regulations related to anatomy.

Tanzania society is very dynamic, enriched with diversity of religious, culture, and tradition belief that are fundamental in introducing the bequest program concept. Raising awareness among members of anatomy departments and the general public has successfully toppled challenges related to long held religious, cultural, and tradition beliefs that are against the donation of human bodies for anatomical dissection in Israel, India, and China, New Zealand, and South Africa [3, 6, 12, 17, 18].

Explicit discussion on the usefulness of the practice and potential disadvantages associated with it will build trust among the community members. This will stimulate dialogue among medical professionals and the community as whole. Cornwall et al. [3] found that most donors were influenced to enroll into body donation registrar by television and Internet advertisements. In Tanzania and Africa at large, these media are viable options given the facts that most households in urban setting have access to television sets and Internet capable handsets. Many youths are actively participating in social media. Again this is an area that can be exploited to the bequest program advantage in raising awareness. Cornwall et al. [3] founded that potential donors had generous tendencies, and were fairy educated. In addition, people with advanced age are more likely to donate their bodies. On the other hand, professional and managerial positions and high spiritual or religious affiliations were among unfavorable factors for body donation. Furthermore, medical students, physicians, and anatomists' were the most reluctant group to enroll into full body donation. Probably the dissectors do not want to be dissected by their peers. According to Pew forum 
on religion and public life, 2010, about $93 \%$ of 45 million Tanzanian people are committed religion practitioners, of which about $60 \%$ are Christian and about 32\% are Muslims. Considering all these and the fact that Tanzania is comprised of mostly black population, it seems as if everything is against body bequest program in Tanzania. When giving public education, it is important to bear these facts in mind so that appropriate interventions to targeted groups are achieved.

5.1.3. Eliminate Negative Signals. The fear that the bodies of donors may not be treated with dignity and respect scares off potential donors from donating their bodies [12]. Commitment of medical schools to respect, honor, and professional conducts on handling donated bodies is important to assure potential donors. Anatomy labs must be sensitive in handling cadaver from the time they are received, during dissections and proper final disposal of the remnants of dissections. On 21st June, 2014, Tanzania and international communities were shocked to the news from one of local television channel that aired about the discovery of cadaver-remains at landfill site in Bunju suburb of Dar es salaam. This high level of disregard for human-remains is catastrophic in the establishing human bequest program in Tanzania $[19,20]$. Such unethical conducts deter the public from registering for the body bequest program and must be avoided at all costs by all departments of anatomy in Tanzania. Positive respectable gestures such as referring to cadaver as "silent teacher" rather than just anatomy specimen have been shown to influence positive attitude and behavior to medical students toward cadavers [21].

Tanzanian Medical schools must engage with the community in activities such as having commemorating cadaver day on annual basis. This serves as a gesture in extending gratitude to potential body donors for the valuable opportunity they would provide to training and learning anatomy if they consider donating their bodies. Building an altar as part of commemorating cadaver-day may provide bereaves with something to remember of their loved one that donated their bodies for science. It enhances honor, respect, and professional conducts in medical students while doing their dissections. In addition, it enhances public awareness and positively encourages potential donors to register as they become confident that they are going to be honored in the end $[22,23]$.

5.1.4. Learn from Peers. Tanzanian medical schools may learn from Nanjing Medical University in China on establishing bequest program as excellently reviewed by Zhang et al. [17]. In their review, medical schools' efforts are keys to success in body donation program. Similar to Nanjing Medical University in China model, Tanzanian medical schools' efforts can influence changes in government policies and regulations, social recognition, and media [17]. Medical schools need to advocate, coordinate, build, and manage body donation programs since they are beneficiaries. Through advocacy, the government and all other stakeholders will be aware of the importance of the programs. This can easily influence appropriate amendments that are missing in the current Tanzanian Anatomy penal code. Again, just like Nanjing
Medical University in China model, when state policies are in order, Tanzanian medical schools in collaboration with local governments should build stations for donations across all Tanzanian regions or cities where potential donors will be registering. Local donor stations will receive donated bodies and make appropriate preparations and arrangements. As indicated in the review by Zhang et al. [17], medical schools need to develop and stringently execute operational standard guidelines for donation campaigns, registration, counseling, reception of donated bodies, use, follow-up, data management, and commemorative activities to donating members. All these can easily be adapted in Tanzania setting. And finally, medical schools need to coordinate and ensure a smooth running of the program. With efficient medical school efforts to advocate, manage, and coordinate as the beneficiaries, lead in time can be shortened significantly. Within 15 years of bequest program (1997-2012), the Nanjing Medical University in China managed to secure an average of 70 donated bodies per annum that effectively met $100 \%$ of bodies' demands [17].

5.1.5. A Wake-Up Call. There has been a global increased pressure against the use of unclaimed bodies for anatomical dissections by many ethically sensitive scholars $[8,15,24]$. Yet there are many conservative anatomists especially in Africa who opt to stay within their comfort zone by continuing collecting unclaimed bodies while ignoring the obvious ethical trepidations $[5,6]$. Even though it may seem safe today that dissecting unclaimed bodies is under legal protection, anatomists should not make mistake. Laws are subject to changes any time. Tanzanian and African medical schools must not wait for such changes to happen while being unprepared and caught off-guard. Ethical whistle blowers are genuinely and tirelessly making it happen and soon enough necessary law amendments shall be in effect [3]. The time to act is now; let us start exploring other viable and lasting bodies sourcing solutions. For those anatomists who still do not see it happening in foreseeable future, they should learn from history; slave trade was once a legal business but ethically it was flaw. Racial discrimination (apartheid in South Africa) was once legal but ethically unsound. It took ethically sensitive individuals to effect the necessary legislative changes. Necessary changes in anatomy legislative act may happen sooner than anticipated. Changing from this ethically dubious dissection of unclaimed bodies practice to ethically sound use of willfully donated bodies takes substantial lead in time [3].

\section{Conclusion}

Cadaver dissection remained to be indispensable anatomy teaching and learning tool for medical students. Sustainable and regular supply sources of quality human bodies are necessary to ensure medical training through dissection is maintained. At the same time, sensitivity to ethical issues in procuring bodies is paramount. For many decades, unclaimed bodies have served as source of bodies for dissection, but due to ethical flaws and irregularities, medical schools dependent on it have deficit of bodies. 
On the contrary, bequest programs throughout the world have quenched body's demands in most medical schools, and in addition, it is cleared of serious ethical issues. Most medical schools have moved or at least are moving toward bequest programs. To Tanzanian medical schools and African medical schools at large that still depend upon dissection of unclaimed bodies, this serves as a wake-up call. Jumping to the bequest program wagon is no longer an option, but it is a must, and the time is now! Cadaver dissections must stay alive for the good of medical student training and researches.

\section{Conflict of Interests}

Authors declare no conflict of interests.

\section{Acknowledgments}

Authors acknowledge the assistance of Miss Evelyn Konje in data analysis and Mr. Msumeno in data entry.

\section{References}

[1] L.-A. Arráez-Aybar, I. Sánchez-Montesinos, R.-M. Mirapeix, B. Mompeo-Corredera, and J.-R. Sañudo-Tejero, "Relevance of human anatomy in daily clinical practice," Annals of Anatomy, vol. 192, no. 6, pp. 341-348, 2010.

[2] L. A. Arráez-Aybar, J. L. Bueno-López, and B. J. Moxham, 'Anatomists' views on human body dissection and donation: an international survey," Annals of Anatomy-Anatomischer Anzeiger, vol. 196, no. 6, pp. 376-386, 2014.

[3] J. Cornwall, G. F. Perry, G. Louw, and M. D. Stringer, "Who donates their body to science? An international, multicenter, prospective study," Anatomical Sciences Education, vol. 5, no. 4, pp. 208-216, 2012.

[4] E. B. EwonuBari, J. T. Watson, D. S. Amaza, N. M. Madueke, A. A. Donatus, and O. E. Effiong, "Problems and prospects of acquistion of human cadaver for medical education in Nigeria," Journal of the Pakistan Medical Association, vol. 62, no. 11, pp. 1134-1136, 2012.

[5] O. B. Akinola, "Formal body bequest program in Nigerian medical schools: when do we start?" Anatomical Sciences Education, vol. 4, no. 4, pp. 239-242, 2011.

[6] H. Gangata, P. Ntaba, P. Akol, and G. Louw, "The reliance on unclaimed cadavers for anatomical teaching by medical schools in Africa," Anatomical Sciences Education, vol. 3, no. 4, pp. 174$183,2010$.

[7] F. Osuagwu C, I. Imosemi O, and W. Oladejo O, "Sources of cadaver used for dissection at the Ibadan medical school, Nigeria-analysis of a three-year data," African Journal of Biomedical Research, vol. 7, pp. 93-95, 2004.

[8] D. G. Jones and M. I. Whitaker, "Anatomy's use of unclaimed bodies: reasons against continued dependence on an ethically dubious practice," Clinical Anatomy, vol. 25, no. 2, pp. 246-254, 2012.

[9] J. P. Gatica-Araneda and P. Alfaro-Toloza, "Donation of bodies for anatomy teaching in Chile," Anatomical Sciences Education, vol. 7, no. 3, p. 248, 2014.

[10] E. C. Halperin, "The poor, the black, and the marginalized as the source of cadavers in United States anatomical education," Clinical Anatomy, vol. 20, no. 5, pp. 489-495, 2007.
[11] D. C. Humphrey, "Dissection and discrimination: the social origins of cadavers in America, 1760-1915," Bulletin of the New York Academy of Medicine, vol. 49, no. 9, pp. 819-825, 1973.

[12] S. A. Rokade and B. H. Bahetee, "Body donation in India: a review," International Journal of Research in Medical Sciences, vol. 1, no. 3, pp. 173-177, 2013.

[13] Prakash, L. V. Prabhu, A. V. Ranade, S. Madhyastha, and G. Singh, "Donation of bodies for cadaveric dissection in medical colleges," Journal of Punjab Academy of Forensic Medicine \& Toxicology, vol. 6, pp. 17-19, 2006.

[14] M. Anteby and M. Hyman, "Entrepreneurial ventures and whole-body donations: a regional perspective from the United States," Social Science and Medicine, vol. 66, no. 4, pp. 963-969, 2008.

[15] S. Hildebrandt, "Lessons to be learned from the history of anatomical teaching in the united states: the example of the university of michigan," Anatomical Sciences Education, vol. 3, pp. 202-212, 2010.

[16] H. Raphael, "From sacrilege to privilege: the tale of body procurement for anatomical dissection in the United States," The Einstein Journal of Biology and Medicine, vol. 27, no. 1, p. 23, 2011.

[17] L. Zhang, M. Xiao, M. Gu, Y. Zhang, J. Jin, and J. Ding, "An overview of the roles and responsibilities of Chinese medical colleges in body donation programs," Anatomical Sciences Education, vol. 7, pp. 312-320, 2014.

[18] N. Notzer, D. Zisenwine, L. Oz, and Y. Rak, "Overcoming the tension between scientific and religious views in teaching anatomical dissection: the Israeli experience," Clinical Anatomy, vol. 19, no. 5, pp. 442-447, 2006.

[19] A. Famau, Tanzania arrests over Dar es Salaam body parts dump, BBC News Africa, July 2014, http://www.bbc.com/news/ world-africa-28416845.

[20] H. Mwangonde, "Dar medics want IMTU censured in "cadaver parts" saga fallout," The Citizen, 2014, http://www.thecitizen .co.tz/News/IMTU-organs-saga-takes-fresh-twist/-/1840392/ 2395482/-/arvcpiz/-/index.html.

[21] M. Bohl, P. Bosch, and S. Hildebrandt, "Medical students' perceptions of the body donor as a "first patient" or "teacher": a pilot study," Anatomical Sciences Education, vol. 4, no. 4, pp. 208-213, 2011.

[22] T. W. Jones, N. Lachman, and W. Pawlina, "Honoring our donors: a survey of memorial ceremonies in United States anatomy programs," Anatomical Sciences Education, vol. 7, no. 3, pp. 219-223, 2014.

[23] J. G. M. Kooloos, S. Bolt, J. van der Straaten, and D. J. Ruiter, "An altar in honor of the anatomical gift," Anatomical Sciences Education, vol. 3, no. 6, pp. 323-325, 2010.

[24] S. Hildebrandt, "Capital punishment and anatomy: history and ethics of an ongoing association," Clinical Anatomy, vol. 21, no. 1, pp. 5-14, 2008. 

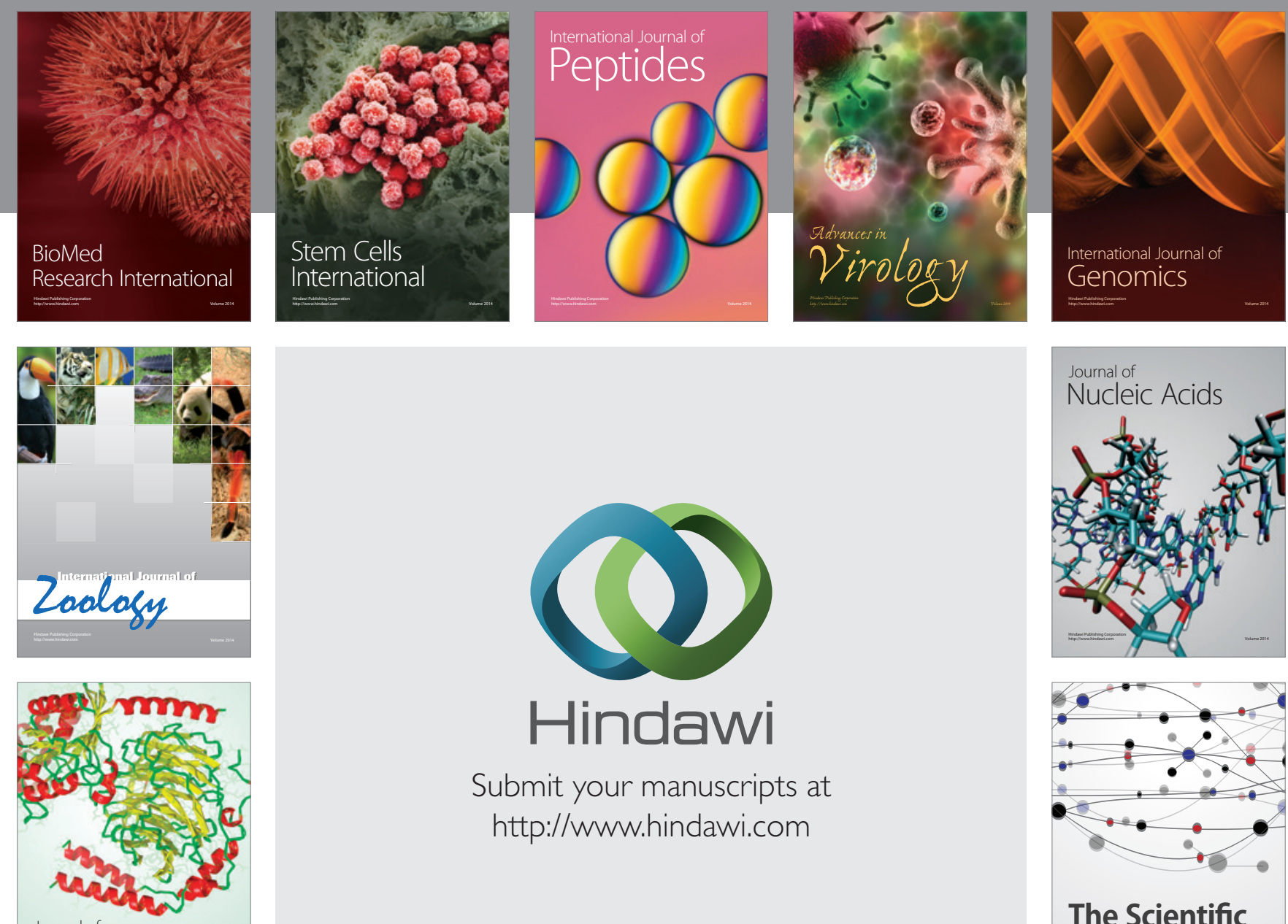

Submit your manuscripts at

http://www.hindawi.com

Journal of
Signal Transduction
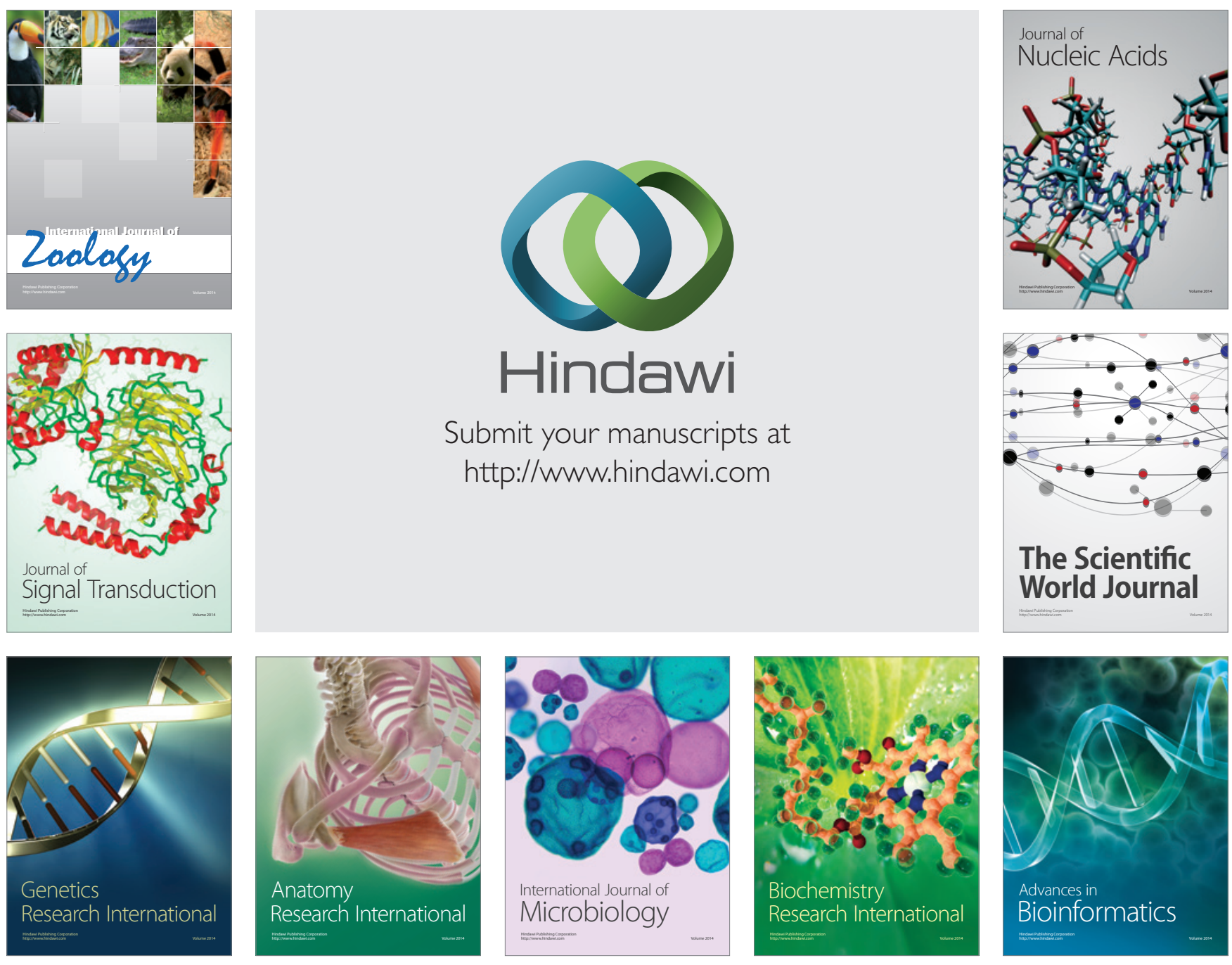

The Scientific World Journal
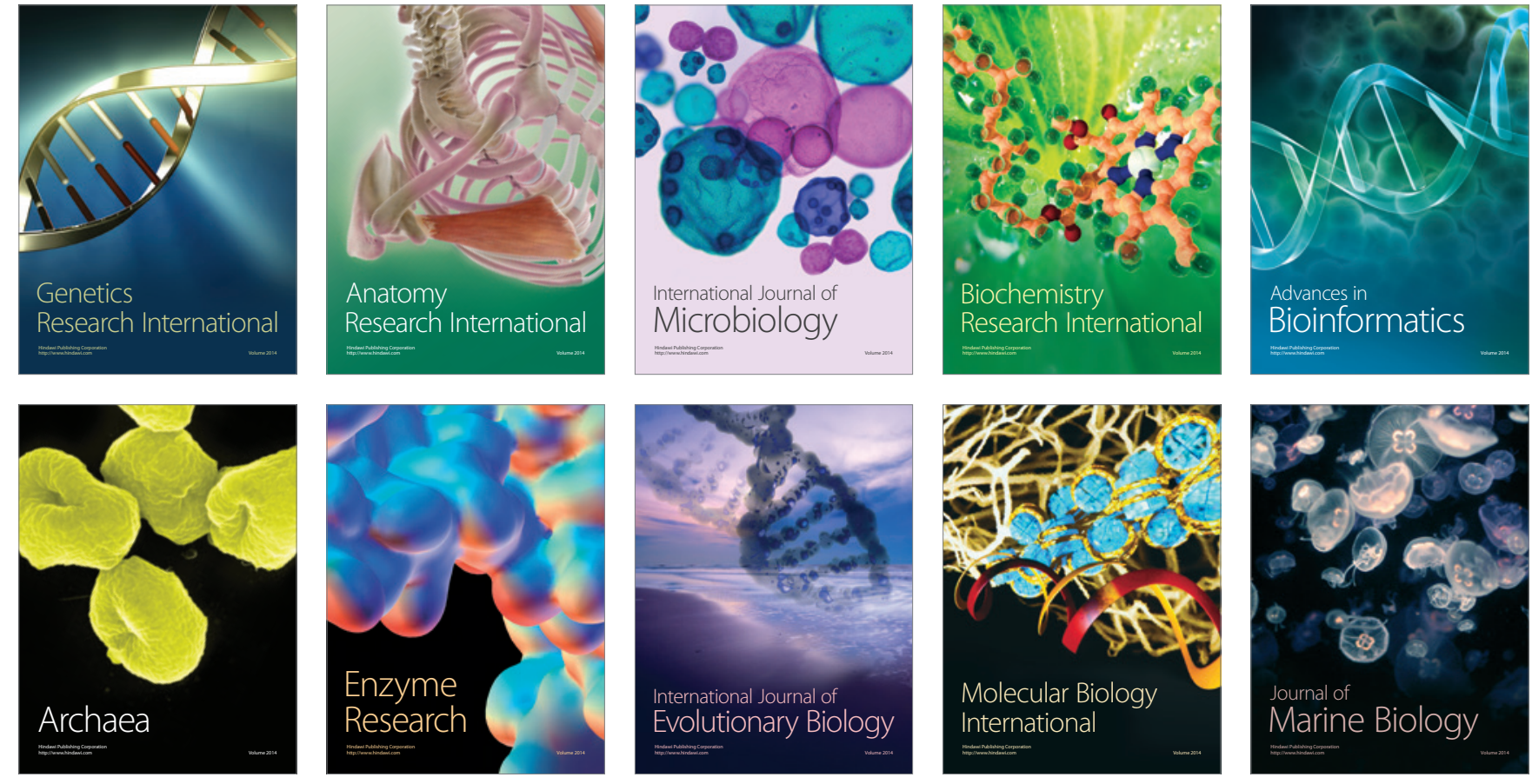